\title{
B-Type Natriuretic Peptide as a Marker of Resuscitation in Patients With Cardiac Arrest Outside the Hospital
}

\author{
Ken Nagao, MD; Nariyuki Hayashi, MD; Katsuo Kanmatsuse, MD*; Satoru Kikuchi, MD*; \\ Kimio Kikushima, MD*; Kazuhiro Watanabe, MD*; Takeo Mukouyama, MD
}

\begin{abstract}
Background Although the circulating concentration of B-type natriuretic peptide (BNP) has both a prognostic and diagnostic value in heart disease, no data are available regarding its resuscitative value for out-of-hospital cardiac arrest.

Methods and Results The present study was a prospective study of 401 patients whose BNP was measured on arrival at the emergency room after an out-of-hospital cardiac arrest with a cardiac cause. The primary endpoint was survival to hospital discharge. The unadjusted rate of survival to hospital discharge decreased in a stepwise fashion among patients in increasing quartiles of BNP concentration $(\mathrm{p}<0.001)$. After adjusting for independent predictors of resuscitation, the odds ratios for survival to hospital discharge in the second, third and fourth quartiles of BNP were 0.13 (95\% confidence interval (CI), 0.04-0.46), 0.10 (95\% CI, 0.03-0.41), and 0.004 (95\% CI, $0.00-0.16$ ), respectively. The BNP cutoff value of $100 \mathrm{pg} / \mathrm{ml}$ for survival had a sensitivity of $83 \%$ and a negative predictive value of $96 \%$.

Conclusions The measurement of BNP was found to provide valuable predictive information for survival to hospital discharge in patients with out-of-hospital cardiac arrest of cardiac etiology. (Circ J 2004; 68: 477482)
\end{abstract}

Key Words: Cardiac arrest; Cardiopulmonary resuscitation; Cardiovascular diseases; Natriuretic peptides; Survival

A chieving the optimal survival rate for out-of-hospital cardiac arrest in every community is the challenge now and in the future ${ }^{1-3}$ Each year some 90,000 people in Japan and 225,000 in the United States and Europe suffer an out-of-hospital cardiac arrest, thus accounting for almost half of all deaths caused by cardiovascular disease ${ }^{2-4}$ The 1-year survival rate after an out-of-hospital cardiac arrest of cardiac origin is extremely low (3\%) in Japan, and although the chain of survival has been shown to have a significant relationship with survival, ${ }^{1,3,5}$ no clinical studies of the cardiac neurohormonal activation of Btype natriuretic peptide (BNP) are available for this cardiac event.

BNP is a cardiac neurohormone synthesized in the ventricular myocardium and secreted from the ventricle as a response to ventricular expansion and pressure overload ${ }^{6-8}$ A-type, B-type and C-type natriuretic peptides are similar in their ability to promote natriuresis and diuresis, inhibit the renin-angiotensin-aldosterone axis and sympathetic activity, and act as vasodilators; however, BNP is a more sensitive and specific indicator of ventricular disorders than the other natriuretic peptides?,10 Clinical studies of heart failure suggest that the BNP concentration can be used to confirm the diagnosis, measure the severity of left ventricu-

(Received December 8, 2003; revised manuscript received February 17, 2004; accepted March 4, 2004)

Departments of Emergency and Critical Care Medicine and *Departments of Cardiology, Nihon University School of Medicine, Tokyo, Japan

Mailing address: Ken Nagao, MD, Department of Emergency and Critical Care Medicine, Surugadai Nihon University Hospital, 1-8-13 Kanda, Surugadai, Chiyoda-ku, Tokyo 101-8309, Japan. E-mail: kennagao@med.nihon-u.ac.jp lar compromise, quantify the functional class, estimate the prognosis and predict future cardiac events, and to evaluate the efficacy of therapy ${ }^{6-14}$ Furthermore, the BNP concentration is also useful for predicting the long-term risk of death and non-fatal cardiac events in patients with acute coronary syndrome (ACS) $9,15,16$

We therefore hypothesized that the BNP concentration could discriminate between survival and death for patients with an out-of-hospital cardiac arrest of cardiac cause.

\section{Methods}

\section{Tokyo Emergency Medical System}

Tokyo has an area of $1,750 \mathrm{~km}^{2}$, and its daytime and nighttime population in 2001 was estimated to be $14,410,382$ and $11,609,869$, respectively. Ambulance units of public emergency medical services in Tokyo consist of 3 emergency medical service personnel, at least one of whom is a licensed emergency life-saving technician. Emergency life-saving technicians are authorized by the Minister of Health, Labor and Welfare to treat cardiac arrest through maintenance of the airway using a laryngeal mask or an esophageal-tracheal combitube, intravenous infusion of extracellular fluid, and defibrillation using a semi-automated external defibrillator. Regulations applying to ambulance units for out-of-hospital cardiac arrest stipulate that emergency life-saving technicians cannot make the decision to stop cardiopulmonary resuscitation and are required to transport patients, excluding any obviously dead individuals, to the nearest emergency hospital. Consequently, more than $95 \%$ of patients with out-of-hospital cardiac arrest are transported under cardiopulmonary resuscitation by emergency medical service personnel each year? The rules of 
Table 1 Baseline Clinical Characteristics According to the Quartile of B-Type Natriuretic Peptide Concentration

\begin{tabular}{|c|c|c|c|c|c|}
\hline & $\begin{array}{c}\text { Quartile } 1 \\
(2.0-33.8 \mathrm{pg} / \mathrm{ml})\end{array}$ & $\begin{array}{c}\text { Quartile 2 } \\
(33.9-152.0 \mathrm{pg} / \mathrm{ml})\end{array}$ & $\begin{array}{c}\text { Quartile } 3 \\
(152.1-392.0 \mathrm{pg} / \mathrm{ml})\end{array}$ & $\begin{array}{c}\text { Quartile } 4 \\
(392.1-2,620 \mathrm{pg} / \mathrm{ml})\end{array}$ & $\begin{array}{l}p \text { value } \\
\text { for trend }\end{array}$ \\
\hline No. of patients & 100 & 100 & 100 & 101 & \\
\hline Age, years & $61.5 \pm 12.9$ & $63.4 \pm 10.2$ & $64.9 \pm 13.4$ & $65.4 \pm 10.6$ & 0.08 \\
\hline Male sex, \% & 80 & 78 & 84 & 79 & 0.7 \\
\hline Location, \% & & & & & 0.02 \\
\hline Home & 22 & 33 & 37 & 43 & \\
\hline Public, indoors & 39 & 34 & 31 & 33 & \\
\hline Public, outdoors & 39 & 33 & 32 & 25 & \\
\hline Witnessed arrest, \% & 56 & 66 & 61 & 54 & 0.3 \\
\hline CPR by bystander, $\%$ & 14 & 13 & 12 & 20 & 0.4 \\
\hline Call-response interval, $\min$ & $5.2 \pm 3.1$ & $5.9 \pm 2.7$ & $5.7 \pm 2.2$ & $5.3 \pm 2.7$ & 0.3 \\
\hline Initial cardiac rhythm, \% & & & & & 0.003 \\
\hline VF or pulseless VT & 52 & 38 & 33 & 31 & \\
\hline Pulseless electrical activity & 10 & 10 & 7 & 8 & \\
\hline Asystole & 38 & 52 & 60 & 61 & \\
\hline Call-to-ER interval, $\min$ & $33.8 \pm 9.8$ & $33.6 \pm 6.9$ & $33.9 \pm 7.1$ & $35.2 \pm 9.4$ & 0.5 \\
\hline ROSC before ER, \% & 18 & 4 & 2 & 1 & $<0.001$ \\
\hline \multicolumn{6}{|l|}{ Cause of arrest, $\%$} \\
\hline Suspected acute coronary syndrome & 86 & 85 & 78 & 69 & 0.007 \\
\hline \multicolumn{6}{|l|}{ Treatment after ROSC, \% } \\
\hline Intra-aortic balloon counterpulsation & 27 & 28 & 30 & 27 & 0.9 \\
\hline Coronary revascularization & 40 & 34 & 30 & 27 & 0.2 \\
\hline Mild hypothermia & 35 & 14 & 11 & 1 & $<0.001$ \\
\hline
\end{tabular}

Data, CPR, cardiopulmonary resuscitation; ER, emergency room; ROSC, return of spontaneous circulation; VF, ventricular fibrillation; VT, ventricular tachycardia. Where applicable, data are mean $\pm S D$.

the Tokyo medical examiner system for out-of-hospital cardiac arrest stipulate that coroners are required to examine the cause of death in patients who do not respond to treatment in the emergency hospital and whose attending physician has been unable to diagnose their disease.

\section{Study Population}

Patients who were transported to the emergency room after an out-of-hospital cardiac arrest were eligible to participate in the study. The inclusion criteria were: age more than 17 years, cardiac arrest prior to the arrival of emergency personnel, and presumed cardiac origin of the arrest according to the Utstein Style ${ }^{17}$ Patients were excluded if they were treated by an emergency cardiopulmonary bypass after failing to respond to standard advanced cardiovascular life support according to the guidelines of the American Heart Association, 1,5 if they had been treated by hemodialysis for chronic renal failure, or if their families refused to provide informed consent to participate in the study.

\section{Data Collection and Treatment}

Blood samples to measure the BNP concentration were taken from a vein before beginning drug administration in the emergency room. Blood was immediately transferred into chilled glass tubes containing an anti-coagulant (disodium ethylenediamine tetraactic acid and aprotinin), centrifuged at $3,000 \mathrm{G}$ for $10 \mathrm{~min}$ at $4^{\circ} \mathrm{C}$, and the plasma was frozen and stored at $-80^{\circ} \mathrm{C}$ until analysis. Plasma BNP was measured using the highly sensitive radioimmunoassay kit of Shiono RIA BNP (Shionogi Co, Ltd), as reported previously?

After the return of spontaneous circulation with standard advanced cardiovascular life support according to the guidelines of the American Heart Association, 1,5 intra-aortic balloon counterpulsation was immediately performed in patients with cardiogenic shock (a systolic blood pressure of less than $90 \mathrm{mmHg}$ for at least $15 \mathrm{~min}$ despite pharmaco- logical therapy, and a heart rate of more than 60 beats $/ \mathrm{min}$ ). In cases of suspected ACS, coronary revascularization was immediately performed if a Thrombolysis in Myocardial Infarction grade 0,1 or 2 flow $^{18}$ was observed in the relevant artery under emergency coronary angiography. Therapeutic hypothermia by coil cooling $\left(34^{\circ} \mathrm{C}\right.$ for more than 2 days) was subsequently performed in comatose survivors whose systolic blood pressure had increased to above $90 \mathrm{mmHg}$. $^{9}$

The data on the cardiac arrest for individual patients were recorded according to the Utstein Style! ${ }^{7}$

\section{Study Endpoints}

The primary endpoint was survival to hospital discharge. The secondary endpoints were a return of spontaneous circulation, defined as the return of a spontaneous palpable pulse and blood pressure for at least $1 \mathrm{~min}^{20}$ admission to the hospital17 a 24-h survival, or a favorable neurological outcome at the time of hospital discharge, defined as a Pittsburgh cerebral-performance category of 1 (good recovery) or 2 (moderate disability) on a 5-category scale. ${ }^{2}$

\section{Statistical Analysis}

The patients were divided into 4 groups according to quartiles of the BNP concentration on arrival at the emergency room. The mean values and proportions of the baseline variables were compared among the quartiles using a one-way analysis of variance for continuous variables, and the Kruskal-Wallis test for categorical variables. The Kruskal-Wallis test was used to evaluate the association between the quartiles of the BNP concentration in all patients, including subgroups of patients and the primary endpoint, and between the quartiles of BNP concentration in all patients and the secondary endpoints. The independent factors associated with the primary endpoint were estimated from a multiple logistic-regression model. Finally, we constructed a receiver-operating-characteristic curve to illustrate the various cutoff values of BNP. 


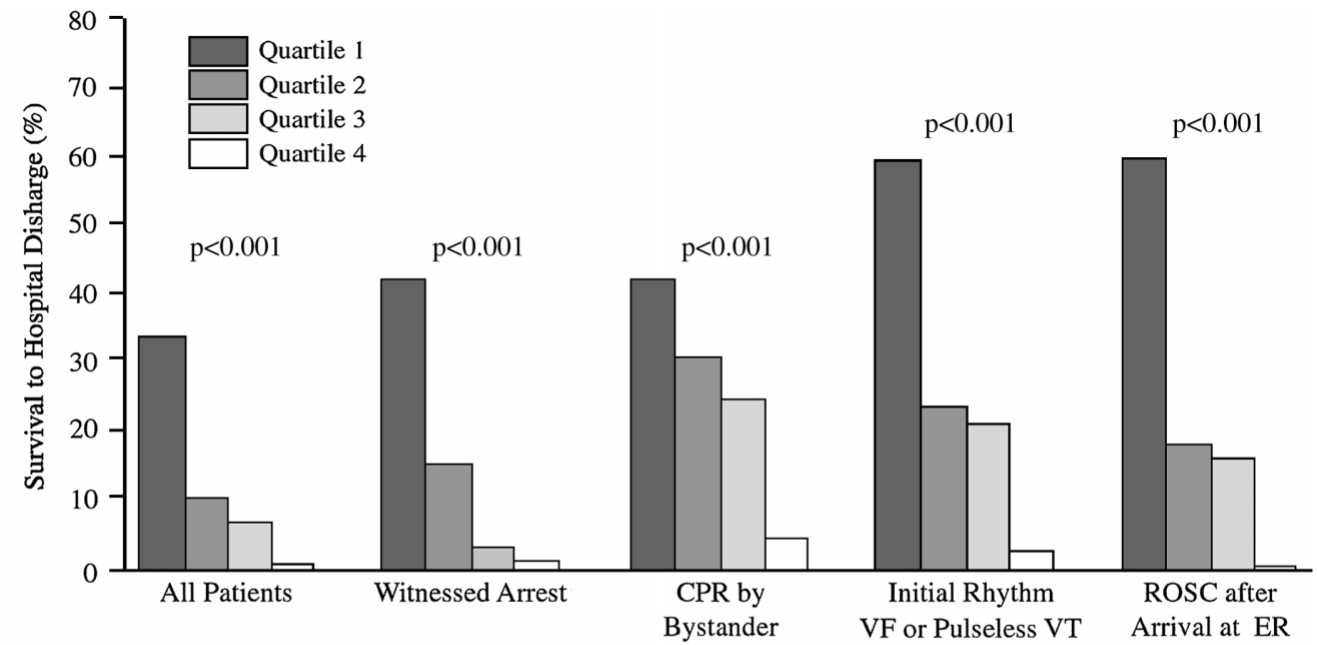

$\begin{array}{crrrrr}\text { No. SuRviving/TotaL No. } & & & & \\ \text { Quartile 1 } & 34 / 100 & 24 / 56 & 6 / 14 & 31 / 52 & 17 / 28 \\ \text { Quartile 2 } & 10 / 100 & 10 / 66 & 4 / 13 & 9 / 38 & 6 / 33 \\ \text { Quartile 3 } & 7 / 100 & 2 / 61 & 3 / 12 & 7 / 33 & 5 / 30 \\ \text { Quartile 4 } & 1 / 101 & 1 / 55 & 1 / 20 & 1 / 31 & 0 / 30\end{array}$

Fig 1. Association between the B-type natriuretic peptide level and the rate of survival to hospital discharge (primary end point) in all patients and in selected subgroups. CPR, cardiopulmonary resuscitation; ER, emergency room; ROSC, return of spontaneous circulation; VF, ventricular fibrillation; VT, ventricular tachycardia. The range of B-type natriuretic peptide levels was as follows: $2.0-33.8 \mathrm{pg} / \mathrm{ml}$ (quartile 1), 33.9-152.0 pg/ml (quartile 2), $152.1-392.0 \mathrm{pg} / \mathrm{ml}$ (quartile 3), and $392.1-2,620.0 \mathrm{pg} / \mathrm{ml}$ (quartile 4). P values are for the trend within each group.

Table 2 Secondary Outcomes According to the Quartile of B-Type Natriuretic Peptide Concentration

\begin{tabular}{|c|c|c|c|c|c|}
\hline & $\begin{array}{c}\text { Quartile 1 } \\
(2.0-33.8 \mathrm{pg} / \mathrm{ml})\end{array}$ & $\begin{array}{c}\text { Quartile 2 } \\
(33.9-152.0 \mathrm{pg} / \mathrm{ml})\end{array}$ & $\begin{array}{c}\text { Quartile } 3 \\
(152.1-392.0 \mathrm{pg} / \mathrm{ml})\end{array}$ & $\begin{array}{c}\text { Quartile } 4 \\
(392.1-2,620 \mathrm{pg} / \mathrm{ml})\end{array}$ & $\begin{array}{l}p \text { value } \\
\text { for trend }\end{array}$ \\
\hline No. of patients & 100 & 100 & 100 & 101 & \\
\hline Return of sportaneous circulation, $\%$ & 46 & 37 & 32 & 31 & 0.1 \\
\hline Admission to hospital, $\%$ & 46 & 28 & 19 & 6 & $<0.001$ \\
\hline 24-h survival, \% & 42 & 20 & 13 & 4 & $<0.001$ \\
\hline Favorable neurologic outcome*, \% & 33 & 8 & 4 & 0 & $<0.001$ \\
\hline
\end{tabular}

*A favorable neurologic outcome was defined as a cerebral-performance category of 1 (good recovery) or 2 (moderate disability).

\section{Results}

\section{Patients Characteristics}

Between January 1996 and December 2001, 822 of the 49,838 patients who suffered an out-of-hospital cardiac arrest in Tokyo were transported to the emergency room of our hospital. A total of 513 patients were assessed for eligibility: 112 met the exclusion criteria, thus 401 patients were enrolled in this study. The BNP concentrations ranged from 2 to $2,620 \mathrm{pg} / \mathrm{ml}$, with a mean $( \pm \mathrm{SD})$ of $236 \pm$ $283 \mathrm{pg} / \mathrm{ml}$, a median of $152 \mathrm{pg} / \mathrm{ml}$, and 25th and 75th percentile values of 33.8 and $392 \mathrm{pg} / \mathrm{ml}$, respectively.

Patients with lower BNP concentrations were more likely than those with higher concentrations to have suffered cardiac arrest in a public place, to have suffered ventricular fibrillation or pulseless ventricular tachycardia in the initial cardiac rhythm, to have a return of spontaneous circulation before reaching the emergency room, and to be suspected of having ACS. The number of patients undergoing therapeutic hypothermia decreased in a stepwise fashion across the increasing quartiles of the BNP concentration $(\mathrm{p}<0.001)($ Table 1$)$.

\section{Outcomes}

A total of 52 of the 401 patients survived to discharge from the hospital and the BNP concentration was lower among such patients than among those who died (mean \pm SD, $74 \pm 95$ vs $260 \pm 266 \mathrm{pg} / \mathrm{ml} ; \mathrm{p}<0.001)$. The primary endpoint of survival to hospital discharge in all patients decreased in a stepwise fashion across the increasing quartiles of the BNP concentration (with quartile 1 at $34 \%$ vs quartile 2 at $10 \%$ vs quartile 3 at $7 \%$ vs quartile 4 at $1 \%$; $\mathrm{p}<0.001)$. This association remained significant in the subgroups of patients with witnessed arrest, cardiopulmonary resuscitation instituted by a bystander, ventricular fibrillation or pulseless ventricular tachycardia in the initial cardiac rhythm, and a return of spontaneous circulation after arrival at the emergency room ( $\mathrm{p}<0.001$, respectively) (Fig 1). The secondary endpoint of without a return of spontaneous circulation also decreased in a stepwise fashion across the increasing quartiles of the BNP concentration $(\mathrm{p}<0.001$, respectively) (Table 2$)$. In the multiple logistic-regression analysis for independent predictors of survival, including age, gender, the presence or absence of witnessed arrest and cardiopulmonary resuscitation instituted by a bystander, the call-response interval, the initial cardiac rhythms at the scene, and the presence or absence 
Adjusted odds ratio

Base-line variable

Age $\geq 65 \mathrm{yr}$

Male sex

Witnessed arrest

CPR by bystander

Call-response interval $\leq 5 \mathrm{~min}$

VF or pulseless VT at initial cardiac rhythm

ROSC before hospital

B-type natriuretic peptide

Quartile 1 (reference group)

Quartile 2

Quartile 3

Quartile 4
Death Survival

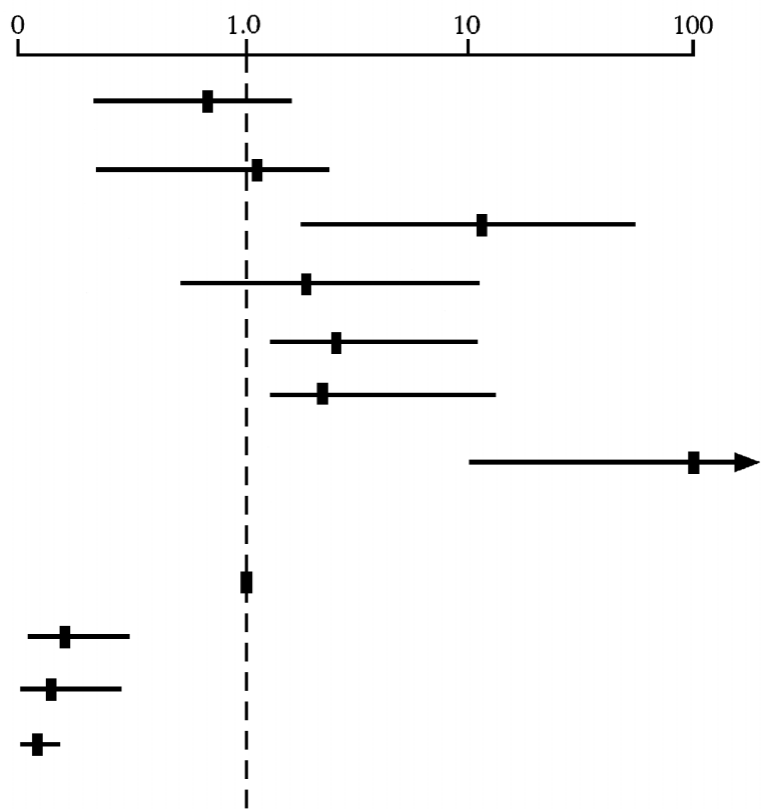

Fig 2. Adjusted odds ratio for survival to hospital discharge according to selected factors, from the multiple logisticregression analysis. Horizontal lines are $95 \%$ confidence intervals. CPR, cardiopulmonary resuscitation; VF, ventricular fibrillation; VT, ventricular tachycardia; ROSC, return of spontaneous circulation.

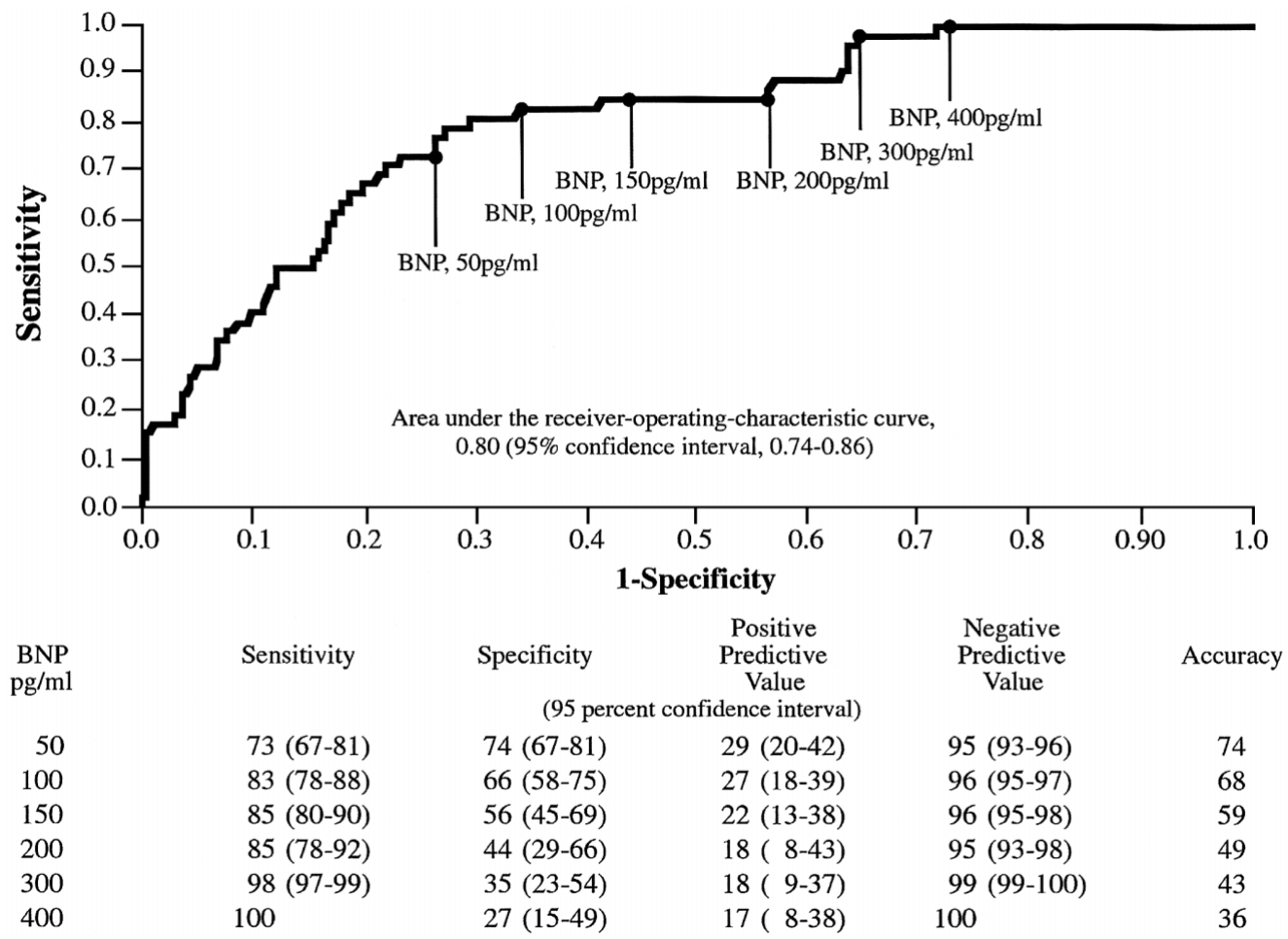

Fig 3. Receiver-operating-characteristic curve for various cutoff levels of B-type natriuretic peptide (BNP) to differentiate survival from death in patients with out-of-hospital cardiac arrest due to cardiac causes.

of a return of spontaneous circulation before arrival at the emergency room, the increasing quartiles of the BNP concentration remained significantly associated with a decreased risk of survival to hospital discharge. The adjusted odds ratios for survival to hospital discharge in the second, third and fourth quartiles of BNP concentration were 0.13 (95\% confidence interval (CI), 0.04-0.46), 0.10 (95\% CI, 0.03-0.41), and 0.004 (95\% CI, 0.00-0.16), respectively (Fig 2). When the age and call-response interval were entered into the model as continuous variables, the 
results remained unchanged.

\section{BNP Threshold}

The capacity of BNP to differentiate survival to hospital discharge from death was assessed with a receiver-operating-characteristic (ROC) curve analysis (Fig 3). The area under the ROC curve was 0.80 (95\% CI, 0.74-0.86; p< $0.001)$. The BNP cutoff value of $100 \mathrm{pg} / \mathrm{ml}$ had the highest combined sensitivity and specificity for the identification of survival to hospital discharge. Higher values were associated with more accurate negative predictive values (for a BNP value of $400 \mathrm{pg} / \mathrm{ml}$, the negative predictive value was $100 \%)$. When a BNP cutoff value of $100 \mathrm{pg} / \mathrm{ml}$ was used in the former multiple logistic-regression model in place of the quartiles of BNP concentration, the results remained unchanged, and a value of $100 \mathrm{pg} / \mathrm{ml}$ or less was the second strongest, independent predictor of survival to hospital discharge, with an adjusted odds ratio of 13.0 (95\% CI, 4.4-38.3).

\section{Discussion}

The present study demonstrated that the BNP concentration on arrival at the emergency room provides valuable information for risk stratification of patients with out-ofhospital cardiac arrest of cardiac origin. Increasing concentrations of BNP were predictive of an increased risk of death in hospital and unfavorable neurologic outcomes at the time of hospital discharge. A multiple logistic-regression analysis showed BNP to be a strong independent factor in survival to hospital discharge. Finally, we determined the optimal cutoff point for BNP regarding survival to hospital discharge to be $100 \mathrm{pg} / \mathrm{ml}$.

Despite the absence of studies evaluating the BNP concentrations in patients with out-of-hospital cardiac arrest, 2 large-scale studies of BNP have been reported!1,16 One is a study of the prognostic value of BNP in patients with $\operatorname{ACS}^{16}$ in which a total of 2,525 patients with ACS were divided into quartiles based on their BNP concentrations within the first few days after the onset of ischemic symptoms. The BNP concentrations ranged from 5 to $1,456 \mathrm{pg} / \mathrm{ml}$ with a median of $81 \mathrm{pg} / \mathrm{ml}$, and a high concentration of BNP was associated with an increased long-term risk of death and non-fatal cardiac events. Our study patients were also divided into quartiles according to their BNP concentrations on arrival at the emergency room, but their BNP concentrations differed from those in the study of ACS because it was presumed that $21 \%(83 / 401)$ of the present patients suffered from other heart disease including heart failure without ACS, hypertrophic cardiomyopathy, myocarditis, electrophysiological cardiac arrest etc. Moreover, the time interval from onset to enrollment into the study was shorter in the present study than that in the patients with ACS. Although the level of expression of the BNP gene in the left ventricle tripled within $4 \mathrm{~h}$ of a coronary ligation in an animal model22 the BNP concentration increased rapidly and transiently after exercise testing in patients with stable angina, after uncomplicated percutaneous transluminal coronary angioplasty, and after the onset of unstable angina. ${ }^{23-26}$

We measured the BNP concentration once, within approximately $1 \mathrm{~h}$ of the cardiac arrest, and it is not possible to determine whether BNP is reflective of sudden cardiac arrest or of a pre-existing ventricular dysfunction from a single measurement. Half of the patients who die of acute myocardial infarction do so before reaching a hospital and in most of these deaths the presenting rhythm is ventricular fibrillation. ${ }^{27-30}$ In the patients who were suspected to have ACS in the present study, a low concentration of BNP may indicate that the time interval from the onset of ischemic symptoms to the incidence of primary ventricular fibrillation, which occurs during the first few hours of the onset as an acute electrical event, is short. On the other hand, a high concentration of BNP may indicate that the interval is long or that secondary ventricular fibrillation, which is associated with heart failure or cardiogenic shock complicating ACS, has occurred.

In a previous study of out-of-hospital cardiac arrest ${ }^{31}$ we observed significantly different concentrations of BNP on arrival at the emergency room between patients with cardiac causes and those with non-cardiac causes (a median of $137 \mathrm{pg} / \mathrm{ml}$ in the cardiac cases $\mathrm{vs} 13 \mathrm{pg} / \mathrm{ml}$ in the non-cardiac cases, $\mathrm{p}<0.001)$. These findings suggest that the higher the stress of ventricular wall tension, the greater the concentration of BNP produced and released into the bloodstream on arrival at the emergency department.

Two large-scale studies reported the BNP threshold to be $80 \mathrm{pg} / \mathrm{ml}$ for the long-term risk of death in ACS 16 and $100 \mathrm{pg} / \mathrm{ml}$ for the diagnosis of congestive heart failure ${ }^{11}$ We also evaluated the cutoff point for survival to hospital discharge and found that concentrations of $100 \mathrm{pg} / \mathrm{ml}$ or less for BNP were a strong, independent predictor of survival. Furthermore, no patients whose BNP concentration had increased $400 \mathrm{pg} / \mathrm{ml}$ or more survived to discharge from hospital. A BNP value of $80-100 \mathrm{pg} / \mathrm{ml}$ may thus have a common threshold in the acute phase of heart disease.

Patients with lower BNP concentrations were more likely than those with higher concentrations to undergo therapeutic hypothermia after return of spontaneous circulation. Shock after return of spontaneous circulation was one of the exclusion criteria of therapeutic hypothermia in the 2 randomized clinical studies, $4,32,33$ which was similar to the criteria of therapeutic hypothermia in the present study. Our recent study of therapeutic hypothermia after return of spontaneous circulation showed the BNP concentration to be one of the predictors of a favorable neurologic outcome 34 The results of the present study suggest that the BNP concentration may be a useful marker of resuscitation in patients with out-of-hospital cardiac arrest of cardiac origin.

\section{Study Limitations}

It was not multicenter study for cardiopulmonary resuscitation after out-of-hospital cardiac arrest. The frequency of survival to hospital discharge in the present study, which included patients treated with intra-aortic balloon counterpulsation, coronary revascularization or mild hypothermia, was higher than that in Japanese multicenter studies ${ }^{35-37}$ of treatment with standard cardiopulmonary resuscitation. If the cause of the cardiac arrest or the cardiac resuscitation treatment and postresuscitation care are investigated in detail, or if BNP is measured using a rapid (15-min) wholeblood assay, ${ }^{11}$ the cutoff point and upper limit of BNP concentration for survival to hospital discharge might change slightly.

In conclusion, we found that the concentration of BNP on arrival at the emergency room after an out-of-hospital cardiac arrest of cardiac origin can provide valuable information regarding the risk stratification of survival, a result that extends the utility of measuring the BNP concentration. 


\section{References}

1. The American Heart Association in Collaboration with the International Liaison Committee on Resuscitation. Guidelines 2000 for Cardiopulmonary Resuscitation and Emergency Cardiovascular Care: An international consensus on science. 3. Adult basic life support, 4. The automated external defibrillator, 5. New guidelines for first aid and 6. Advanced cardiovascular life support. Circulation 2000; 102(Suppl I): I-86-I-171

2. Eisenberg MS, Mengert TJ. Cardiac resuscitation. $N$ Engl J Med 2001; 344: 1304-1313.

3. Nagao K, Hayashi Y, Kanmatsuse K. Cardiopulmonary cerebral resuscitation in the 21st century for out-of-hospital cardiac arrest. $J$ Jpn Soc Intensive Care Med 2002; 9: 11-21 (in Japanese).

4. Curfam GD. Hypothermia to protect the brain. N Engl J Med 2002; 346: 546.

5. Emergency Cardiac Care Committee and Subcommittees, American Heart Association. Guidelines for cardiopulmonary resuscitation and emergency cardiac care. JAMA 1992; 268: 2171-2295.

6. Yasue H, Yoshimura M, Sumida H, Kikuta K, Kujiyama K, Jougasaki $\mathrm{M}$, et al. Localization of mechanism of secretion of B-type natriuretic peptide in comparison with those of A-type natriuretic peptide in normal subjects and patients with heart failure. Circulation 1994; 90: 195-203.

7. Wiese S, Breyer T, Dragu A, Wakili R, Burkard T, SchmidtsSchweda S, et al. Gene expression of brain natriuretic peptide in isolated atrial and ventricular human myocardium: Influence of angiotensin II and diastolic fiber length. Circulation 2000; 102: 3074-3079.

8. Maeda K, Tsutamota T, Wada A, Hisanaga T, Kinoshita M. Plasma brain natriuretic peptide as a biochemical marker of high left ventricular end-diastolic pressure in patients with symptomatic left ventricular dysfunction. Am Heart J 1998; 135: 825-832.

9. Baugham KL. B-type natriuretic peptide: A window to the heart. $N$ Engl J Med 2002; 347: 158-159.

10. McDonagh TA, Robb SD, Murdoch DR, Morton JJ, Ford I, Morrison $\mathrm{CE}$, et al. Biochemical detection of left-ventricular systolic dysfunction. Lancet 1998; 351: 9-13.

11. Maisel AS, Krishnaswamy P, Nowak R, McCord J, Hollander JE, Duc P, et al. Rapid measurement of B-type natriuretic peptide in the emergency diagnosis of heart failure. $N$ Engl J Med 2002; 347: 161 167.

12. Patel AR, Konstam MA. Recent advances in the treatment of heart failure. Circ J 2002; 66: 117-121.

13. Ogawa K, Oida A, Sugimura H, Kaneko N, Nogi N, Hasumi M, et al. Clinical significance of blood brain natriurtic peptide concentration measurement in the detection of heart disease in untreated outpatients: Comparison of electrocardiography, chest radiography and echocardiography. Circ J 2002; 66: 122-126.

14. Koseki Y, Watanabe J, Shinozaki T, Sakuma M, Komaru T, Fukuchi $\mathrm{M}$, et al. Characteristics and 1-year prognosis of medically treated patients with chronic heart failure in Japan: Chronic heart failure analysis registry in Tohoku district (CHART). Circ J 2003; 67: 431 436.

15. Richards AM, Nicholls MG, Yandle TG, Frampton C, Espiner EA, Turner JG, et al. Plasma N-terminal pro-brain natriuretic peptide and adrenomedullin: New neurohormonal predictors of left ventricular function and prognosis after myocardial infarction. Circulation 1998; 97: $1921-1929$.

16. de Lemos JA, Morrow DA, Bentley JH, Omland T, Sabatine MS, $\mathrm{McCabe} \mathrm{CH}$, et al. The prognostic value of B-type natriuretic peptide in patients with acute coronary syndromes. $N$ Engl J Med 2001; 345: $1014-1021$

17. Cummins RO, Chamberlain DA, Abramson NS, Allen M, Baskett PJ, Backer L, et al. Recommended guidelines for uniform reporting of data from out-of-hospital cardiac arrest: The Utstein Style: A statement for health professionals from a task force of the American Heart Association, the European Resuscitation Council, the Heart and Stroke Foundation of Canada, and the Australian Resuscitation Council. Circulation 1991; 84: 960-975.

18. Chesebro JH, Knatterud G, Roberts R, Borer J, Cohen LS, Dalen J, et al. Thrombolysis in Myocardial Infarction (TIMI) Trial, phase I: A comparison between intravenous tissue plasminogen activator and intravenous streptokinase: Clinical findings through hospital discharge. Circulation 1987; 76: 142-154.

19. Nagao K, Hayashi N, Kanmatsuse K, Arima K, Ohtsuki J, Kikushima $\mathrm{K}$, et al. Cardiopulmonary cerebral resuscitation using emergency cardiopulmonary bypass, coronary reperfusion therapy and mild hypothermia in patients with cardiac arrest outside the hospital. $\mathrm{J} \mathrm{Am}$ Coll Cardiol 2000; 36: 776-783.

20. Gueugniaud PY, Mols P, Goldstein P, Pham E, Dubien PY, Deweerdt $\mathrm{C}$, et al. A comparison of repeated high doses and repeated standard doses of epinephrine for cardiac arrest outside the hospital. $N$ Engl $J$ Med 1998; 339: 1595-1601.

21. Safar P, Bircher NG. Cardiopulmonary cerebral resuscitation: Basic and advanced cardiac and trauma life support: An introduction to resuscitation medicine, 3rd ed. London: WB Saunders; 1988; 267.

22. Hama N, Itoh H, Shirakami G, Nakagawa O, Suga S, Ogawa Y, et al. Rapid ventricular induction of brain natriuretic peptide gene expression in experimental acute myocardial infarction. Circulation 1995; 92: $1558-1564$.

23. Marumoto K, Hamada M, Hiwada K. Increased secretion of atrial and brain natriuretic peptides during acute myocardial ischaemia induced by dynamic exercise in patients with angina pectoris. Clin Sci (Colch) 1995; 88: 551-556.

24. Kikuta K, Yasue H, Yoshimura M, Morita E, Sumida H, Kigiyama K, et al. Increased plasma concentrations of B-type natriuretic peptide in patients with unstable angina. Am Heart J 1996; 132: 101-107.

25. Talwar S, Squire IB, Downie PF, Davies JE, Ng LL. Plasma N terminal pro-brain natriuretic peptide and cardiotrophin I are raised in unstable angina. Heart 2000; 84: 421-424.

26. Kyriakides ZS, Markianos M, Michalis L, Antonladis A, Nikolaou NI, Kremastinos DT. Brain natriuretic peptide increases acutely and much more prominently than atrial natriuretic peptide during coronary angioplasty. Clin Cardiol 2000; 23: 285-288.

27. National Heart Attack Alert Program Coordination Committee, Emergency Department 60 Minutes to Treatment Working Group. Rapid identification and treatment of patients with acute myocardial infarction. Ann Emerg Med 1994; 23: 311-329.

28. Ryan TJ, Anderson JL, Antman EM, Branff BA, Brooks NL, Califf RM, et al. ACC/AAH guidelines for the management of patients with acute myocardial infarction: A report of the ACC/AHA Task Force on practice guidelines (Committee on Management of Acute Myocardial Infarction). J Am Coll Cardiol 1996; 28: 1328-1428.

29. Task Force on Management of Acute Myocardial Infarction of the European Society of Cardiology. Acute myocardial infarction: Prehospital and in-hospital management. Eur Heart J 1996; 17: 11401164.

30. O'Doherty M, Taylor DI, Quinn E, Vincent R, Chamberlain DA. Five hundred patients with myocardial infarction monitored within one hour of symptoms. BMJ 1993; 286: 1405-1408.

31. Nagao K, Kanmatsuse K, Watanabe I, Ouguchi S, Kikuchi S, Shioiri $\mathrm{K}$, et al. The diagnostic and prognostic values of a BNP in patients with out-of-hospital cardiac arrest (abstract). J Jpn Soc Internal Med 2002; 91: 192 (in Japanese).

32. The Hypothermia After Cardiac Arrest Group. Mild therapeutic hypothermia to improve the neurologic outcome after cardiac arrest. N Engl J Med 2002; 346: 549-556.

33. Bernard SA, Gray TW, Buist MD, Jones BM, Silvester W, Gutteridge $\mathrm{G}$, et al. Treatment of comatose survivors of out-of-hospital cardiac arrest with induced hypothermia. N Engl J Med 2002; 346: 557563.

34. Nagao K, Hayashi N, Kikushima K, Watanabe K, Iida K, Mukoyama $\mathrm{T}$, et al. The relationship between B-type natriuretic peptide and the neurologic outcome in comatose survivors treated with mild hypothermia after cardiac arrest (abstract). Circulation 2003; 108: IV317.

35. Hayashi Y, Hiraide A, Morita H, Shinya H, Nishiuchi T, Mukainaka $\mathrm{S}$, et al. An analysis of time factors in out-of-hospital cardiac arrest in Osaka, Japan. Resuscitation 2002; 53: 121-125.

36. Mashiko K, Otsuka T, Shimazaki S, Kohama A, Kamishima G, Katsurada K, et al. An outcome study of out-of-hospital cardiac arrest using Utstein template: A Japanese experience. Resuscitation 2002; 55: $241-246$.

37. The SOS-KANTO committee. Survey of survivors after cardiac arrest in the Kanto area; SOS-KANTO, the result of initial totaling. KANTO Journal of Japanese Association for Acute Medicine 2003; 24: 10-16 (in Japanese). 